\title{
Influence Characteristics of Double-Stratum Hard Roof Movement in a Fully Mechanized Top Coal Caving on the Working Resistance of Supports
}

\author{
Wenbao Shi ${ }^{1}$, Zhiqiang Yin ${ }^{1, *}$, Yan Li $^{2}$, Jucai Chang ${ }^{1}$ and Xianhua Miao ${ }^{3}$ \\ ${ }^{I}$ Key Laboratory of Safe and Effective Coal Mining, Ministry of Education, Anhui University of Science and Technology, Huainan \\ 232001, China \\ ${ }^{2}$ School of mechanical and electrical engineering, Huainan Normal University, Huainan 232001, China \\ ${ }^{3}$ Shanxi Jinyuan Zhaoxian Mining Industry Co., Ltd., Baoji 721000, China
}

Received 27 October 2019; Accepted 15 January 2020

\begin{abstract}
In the traditional mechanical models of hard roof, multiple hard rock strata are usually taken as the overall critical stratum to analyze its movement instability characteristics while the mutual effect between two hard rock strata is neglected, so it's difficult for theoretical analysis results to realize the accurate prediction of mine pressure behaviors. The reasonable prediction of mine pressure behaviors on a fully mechanized caving face with multiple hard rock strata is ensured further by considering the geological conditions of the 1307 working face mine in Zhaoxian Coal Mine in the Yonglong Coalfield Mine area in China, a mechanical model of a hard roof structure with high and low strata (double strata) was proposed in this study, and the periodic instability step of the high- and low-level hard roofs and the change laws of support resistance on the working face were also determined. Then, the theoretical calculation results were verified according to field measurement data. Results indicate that fracturing instability does not simultaneously occurred in the high and low strata of the hard roof, as the instability steps are $106 \mathrm{~m}$ and $18 \mathrm{~m}$, and the corresponding working resistances of the hydraulic support are $63 \mathrm{MPa}$ and $37 \mathrm{MPa}$, respectively. Meanwhile, the onsite-measured mine pressure data suggest that the major-cycle cyclic weighting step is approximately $101 \mathrm{~m}$, while the continuous step is approximately $12 \mathrm{~m}$. The minor-cycle cyclic weighting step is within $15-25 \mathrm{~m}$, the continuous step is approximately $2 \mathrm{~m}$, and the peak working resistances of the hydraulic support on the average are $42.3 \mathrm{MPa}$ and $36.8 \mathrm{MPa}$, respectively, so the on-site monitoring data basically accorded with the theoretical analysis results, thus verifying the scientificity of the constructed mechanical model. This study provides a theoretical reference on the safe mining of the fully mechanized caving face of a multi-stratum hard roof.
\end{abstract}

Keywords: Double-stratum hard roof, Fully mechanized top coal caving, Movement characteristics of overlying strata, Working resistance of supports, Mine pressure behaviors

\section{Introduction}

Coal is the main energy source in China, where coal reserves in Northwest China account for nearly $80 \%$ of total coal reserves, and coal reserves in northwest region have massively thick coal seams [1]. The primary mining method adopted according to the occurrence conditions of the thick coal seams in northwest region is the fully mechanized top coal caving, which has greater mining height compared with ordinary mining, so more intense impact load can be generated when the overlying roof at the coal seam collapses; In the meantime, this can further increase the height of the overlying "three zones" in the stope, and the possibility of two or more hard rock strata in the caving zone may further increase [2]. The overlying multiple hard rock strata in the stope can experience fracturing and collapse in different steps with the mining of the working face. However, predicting the fracturing instability cycle is difficult, as impact energy forms due to the increase in collapse instability. This situation leads to major difficulties to the support management of the working face and roof management, and it severely threatens the safe production of coal mine enterprises [3]. Therefore, it's necessary to

*E-mail address: zhqyin@aust.edu.cn ISSN: 1791-2377 @ 2020 School of Science, IHU. All rights reserved. doi:10.25103/iestr.131.08 reasonably analyze the stress state of hard roof at different overlying strata on the fully-mechanized caving face, propose reasonable mechanical model of multi-stratum hard roof and investigate its mine pressure behaviors and change laws of working resistance of supports.

In comparison with conventional working face of traditional single-stratum hard roof, the mining height of a fully mechanized caving face of a multi-stratum hard roof can be greater than that of the conventional working face of a traditional single-stratum hard roof. Gangues caving from the low rock strata cannot easily fill the goaf, and the high hard rock strata can be influenced by mining, causing a nonsynchronous fracture of these hard rock strata. Moreover, low-level rock strata fracturing can influence high-level rock strata fracturing, causing additional drastic mine pressure behaviors [4]. Among the existing studies on reasonable initial and periodic fracturing span and intensity of hard roofs, many scholars have proposed the adoption of "Reissner thick plate" theory [5,6], "Vlasov plate" theory [7, $8]$, and "long beam" theory $[9,10]$, which provide a precious theoretical basis for hard roof control. However, the calculation and analytical results obtained using a single theory somewhat deviate from engineering practice when the complexity of overlying strata collapse on fully mechanized caving faces in multi-stratum hard roofs, the different structural characteristics of the overlying strata at the 
fracture of each stratum of the hard roof, and the varying stress environments are altogether considered.

A multi-stratum hard roof not only can change the movement of the overlying strata but also can directly affect the change laws of support resistance of the working face. In this study, a fracture stress-bearing model is constructed to investigate the deformation and fracture characteristics of a multi-stratum hard roof on a fully mechanized caving face and determine the movement of the overlying strata and the change laws of working resistance of the supports.

\section{State of the art}

The movement characteristics of overlying hard rock strata of working faces have always been a popular topic in the field of mining safety. Thus, domestic and foreign scholars have adopted theoretical analysis and the finite element numerical simulation method to extensively study the overlying strata structures and the mine pressure behaviors of the stope, and given some computation methods applicable to engineering practice. However, the previous studies have mainly concentrated on the fracturing instability process of overlying hard rock strata in stopes and the fracturing span and working resistance of supports on working faces. Qian [11] proposed key strata theory to investigate the overlying strata activities in a stope by theoretically analyzing and establishing the criteria for key strata. The theoretical result was extensively used to analyze and predict the movement laws of overlying strata of the working face of the hard roof. $\mathrm{Li}$ [12] proposed six movement models of overlying strata that entailed theoretical analyses and numerical simulation: direct caving, bidirectional rotation and secondary rotation of cantilever beam structure, hinged structure of rock mass, masonry beam structure and short masonry beam structure. The calculation models of the working resistance of the support under different movement types were established in succession, and the onsite measurement data were verified. Verma and Deb [13, 14] modified the load estimation method according to the structural characteristics of overlying strata of a working face under hard roof conditions and acquired the computation method for the working resistance of hydraulic supports on a fully mechanized caving face for a thick coal seam under hard roof condition. The hanging arch length of the key strata on the roof and the influence factors of its caving and fracturing were obtained by combining the theoretical analyses of the cantilever beam. Golab [15] investigated the stability of a roof at the end of a working face by combining theoretical analysis, numerical simulation, and onsite measurement. The results showed that with the top coal caving face of an inclined long wall (particularly after the overlying strata have caved), the immediate roof and the basic roof can form "cantilever beam" and "masonry beam" structures, respectively. The load borne by the coal pillars was found to be related to the length of the key rock mass and the fracturing position. Chen [16] derived the calculation equations of elasticity modulus, bearing load, and limit span of multiple key strata under overlying multi-stratum hard roof condition, proposed the judgment curves of instability types of fracturing rock masses for the multiple key strata, and further perfected the theory of combinational key strata. Sainsbury [17] and Wang et al. [18] used the UDEC (Universal Distinct Element Code) software to systematically study the existing prominent problems of multi-stratum hard roof control and obtained mine pressure behaviors under the initial and periodic collapse of the immediate roof and the basic roof on the multi-stratum hard roof. By taking the overlying hard and soft alternate rock strata in a stope as study objects, Zhou [19] combined numerical simulation, theoretical analysis, and analog simulation to determine the fracturing instability step of the key strata on a compound roof. Results showed that the first to third hard rock strata have successively experienced a fracture on the roof of the working face, and they represent the sub-key strata of the roof, while the compound key stratum consisting of the fourth to sixth hard rock strata corresponds to the main key stratum of the roof. The average fracturing step of the main key strata on the compound roof was calculated as $114 \mathrm{~m}$. When the working face advanced to $108.2 \mathrm{~m}$, the fracture of the main key stratum led to abnormal mine pressure behaviors on the working face. Among the abovementioned studies, the overlying strata structures in stopes are mostly multi-stratum hard roofs with a series of small spacing. The mechanical calculations of the roof fractures were conducted only according to the theory of "beam-type structure," but the non-synchronous fractures of hard roofs under the large strata spacing condition are usually neglected. Deformation instability at the high-level hard rock strata are usually under the action of flexible support of the lower gangues, which by that time may have already fractured and caved, forming new mechanical structural characteristics of the high-level hard roof.

As the mining depth increases, multi-stratum hard rock strata mainly appear in the overlying strata on the fully mechanized caving face. To deeply understand the influence laws of fracture and caving of such multi-stratum hard roofs in relation to the support resistance of a working face, many scholars have adopted the calculation method of support resistance for the working face under the multi-stratum hard rock strata condition. Li [20], Bai [21], and Guo et al. [22] analyzed the stope stresses of compound hard roofs with large mining heights based on key strata theory and obtained reasonable hydraulic support types and their working resistance on the working faces of multi-stratum hard roofs. By using onsite measurement data, Mangal [23] established a calculation model for a cantilever beam at the compound key strata and proposed a calculation method for the working resistance of supports on a working face of a multistratum hard roof. Their study results showed that the fracture mode and the order of multi-stratum hard roof notably influence mine pressure behaviors on the working faces. A single-stratum collapse or the multi-stratum synchronous instability of roofs at the key strata should be able to correspond to the support resistance on the working faces. Under the synchronous instability condition of hard roofs with thick strata, reasonable support requirements for the working face at the ultra-thick coal seam are difficult to satisfy by purely elevating the support resistance. Through field observation, physical simulation, and theoretical analysis, Liang [24] obtained three structural models of the overlying strata formed in different periods during the overlying strata fracturing process of a working face $(7.0 \mathrm{~m}$ in mining height) and proposed a calculation method for the working resistance of hydraulic supports on this working face. Kornowski and Kurzeja [25] conducted a theoretical analysis based on the interactive relation between the immediate roof and the basic roof on a large-mining-height working face and determined the influence characteristics of their interaction on the working resistance of hydraulic supports. They also acquired the load calculation method of hydraulic supports. They determined that the position and 
Wenbao Shi, Zhiqiang Yin, Yan Li, Jucai Chang and Xianhua Miao/

Journal of Engineering Science and Technology Review 13 (1) (2020) 57 - 66

thickness of the hanging arch at the overlying strata on the working face and the maximum fracturing stability step are the critical factors of roof control of the large-mining-height stope and the type selection and calculation of hydraulic supports. The abovementioned studies have mainly simplified multiple hard roc strata into primary and secondary key strata, but they are taken as a whole when analyzing the interactive relation between stope support and surrounding rocks and when constructing the calculation model for the working resistance of stope support. In effect, the calculation results deviate to a certain extent from engineering practice.

The deficiencies of the existing studies are fully considered in the current work. The research background of the present study is the fully mechanized top coal caving of the 1307 working face in Zhaoxian Coal Mine in the Yonglong Coalfield Mine area in China. A mechanical model adaptive to the actual overlying hard roof is constructed to investigate the relationship between the movement instability characteristics of the multi-stratum hard roof and the working resistance of the supports in fully mechanized top coal caving. Then, the theoretical analytical results are verified with field monitoring data to provide a good reference for determining the reasonable working resistance of supports in the fully mechanized top coal caving of the multi-stratum hard roof.

The remainder of this study is presented as follows. Section 3 briefly introduces the engineering geological background, the constructed interactive mechanical model between the support and the surrounding rock in the fully mechanized top coal caving of the high- and low-level hard rock strata, and the calculation and the derivation. Section 4 discusses the theoretical analysis and the field monitoring of the periodic instability step of the high- and low-level hard rock strata and the change laws of working resistance of the stope support. Section 5 summarizes the findings, and related conclusions are given.

\section{Methodology}

\subsection{Geological profile}

Zhaoxian Coal Mine is a typical hard roof mine area with Jurassic coal seams. The mine is located in the northwest part of Linyou County, Baoji City in Shanxi Province and belongs to the Yonglong Coalfield Mine area in the Huanglong Jurassic Coal Field, as shown in Fig. 1.

The 1307 fully mechanized caving face is the primary working face of Zhaoxian Coal Mine and located in the southeast wing of the primary mining area. At the eastern part is an unmined area. The $3 \#$ coal seam in the Jurassic Yanan Formation is mined on the working face. The dip angles of the coal seams range from $3^{\circ}$ to $17^{\circ}$, with an average dip angle of $9^{\circ}$. The thickness of the coal seams is within $4-15 \mathrm{~m}$, and the average thickness is $10.33 \mathrm{~m}$. The planar positional relation of the 1307 working face and the coal seam histogram are shown in Fig. 2.

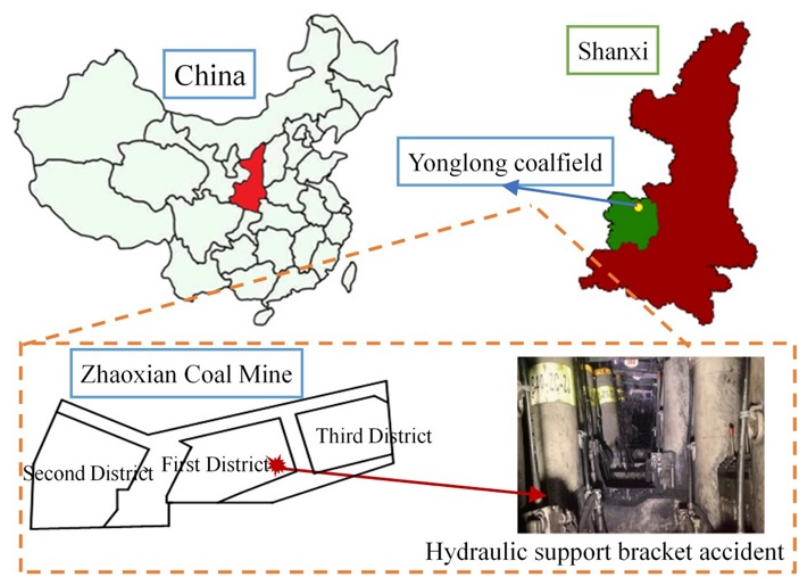

Fig. 1. Geographical location map of Zhaoxian Coal Mine

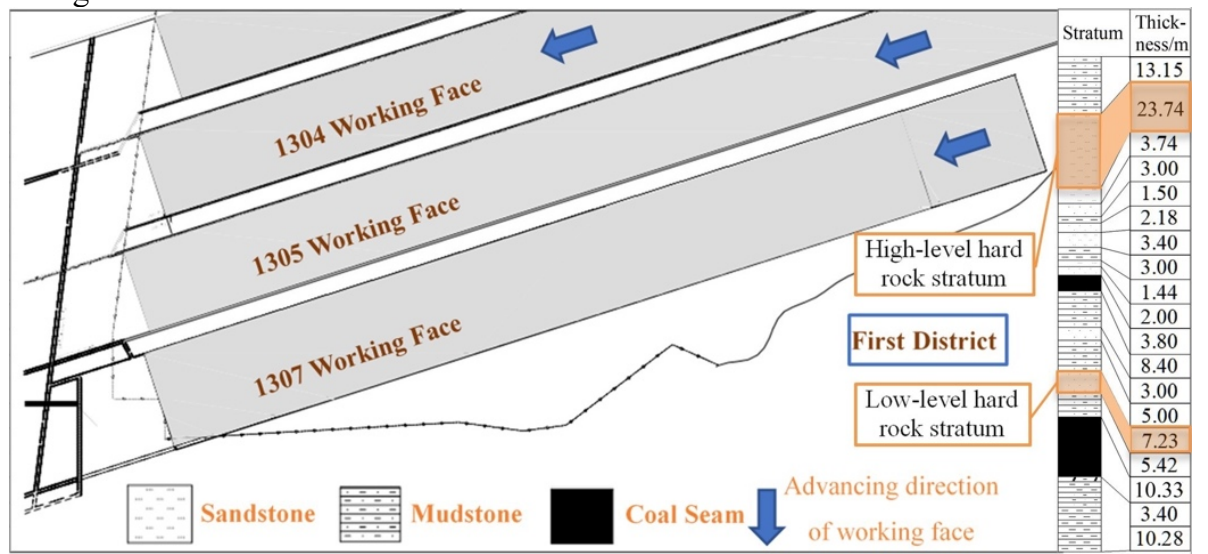

Fig. 2. Comprehensive histogram of coal seams on 1307 working face and roof and floor strata

The 1307 fully mechanized caving face has a length of $155 \mathrm{~m}$. The basic support is a ZF16000/21/38 four-pillar support and a shield-type hydraulic support. The YHJ60 pressure monitoring recorders used for the fully mechanized top coal mining are arranged on 19 supports. The above configurations are shown in Fig. 3. The recorder sensor at each measuring point monitors the working resistances of the left front column and the right rear column. The pressure monitoring sensor can realize real-time measurement and display of the support resistance.

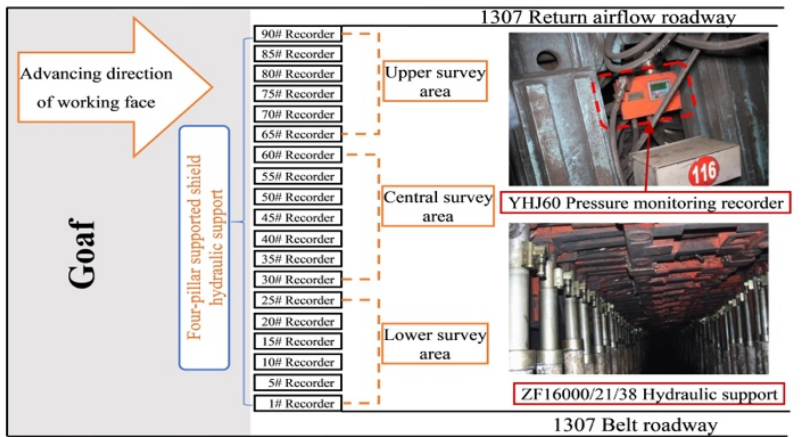

Fig. 3. Pressure recorder layout plan of the hydraulic supports on 1307 working face 
3.2 Mechanical analysis of movement characteristics of multi-stratum hard roof in fully mechanized top coal caving

The mining height of the 1307 fully mechanized caving face in the Zhaoxian Coal Mine is $10.33 \mathrm{~m}$. According to a related study [26], the height of the caving zone is approximately $58.6 \mathrm{~m}$. Within the caving scope above the coal seam, two hard sandstone strata exist at 5.4 and $53.2 \mathrm{~m}$ away from the coal seam roof, and their corresponding thickness values are 7.23 and $23.74 \mathrm{~m}$, as shown in the geological histogram in Fig. 2. The average tensile strength of the sandstone strata is approximately $9.5 \mathrm{MPa}$, which is markedly higher than average tensile strength of $4.2 \mathrm{MPa}$ at the other rock strata. The two strata in the mining process will play a critical role in the fracturing movement of the overlying strata at the coal seam [27]. Therefore, a supportsurrounding rock mechanical model is constructed in the present study for the two-stratum hard roofs above the 1307 fully mechanized caving face. The aim is to investigate the effects of the deformational movements of the high- and low-level hard roofs and their instability processes on the change laws of support resistance on the working face.

3.2.1 Support-surrounding rock relation under the movement instability of the low-level hard rock stratum In the mining process of the 1307 fully mechanized caving face, a collapse of the top coal and the immediate roof will first occur. As the length of the working face along the inclining direction is far greater than the overhanging span of the immediate roof along the pitch, this structure can be regarded a beam structure. Many studies have reported that the hard rock stratum above the immediate roof will gradually collapse and fracture and subsequently form a hinged rock beam structure with the advancement of the working face, and a combinational cantilever beam structure will be easily formed below the hard rock stratum [28]. Therefore, a "combinational cantilever beam-hinged rock beam" structure under the movement instability of the lowlevel hard rock stratum is constructed, in which the pressure borne by the support is divided into two parts: weight of the top coal and immediate roof and deformation pressure of the basic roof. The structural model of the low-level rock stratum is shown in Fig. 4.

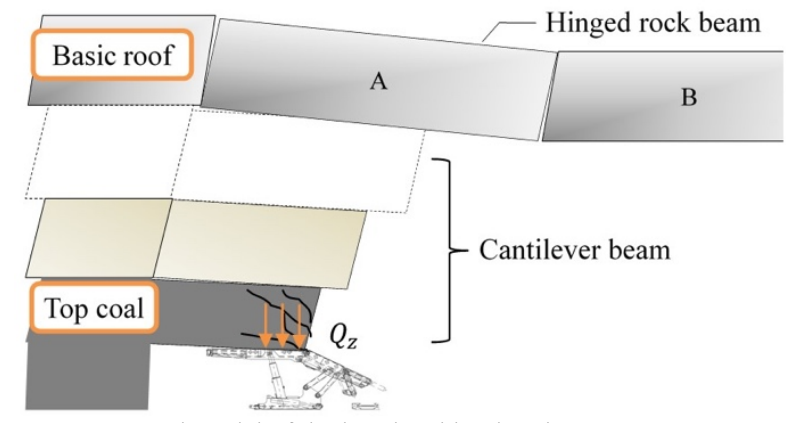

Fig. 4. Structural model of the low-level hard rock stratum

The mechanical analysis model of the cantilever beam on the top coal and the immediate roof is shown in Fig. 5.

When the top coal and the immediate roof are under a bearing state, we can obtain the following structural static mechanical equilibrium condition as follows [29]:

$$
\sum M_{\mathrm{Oj}}=0 \cdot(\mathrm{j}=0,1,2, \cdots, \mathrm{i})
$$

where $M_{\mathrm{Oj}}$ is torque of rock stratum.

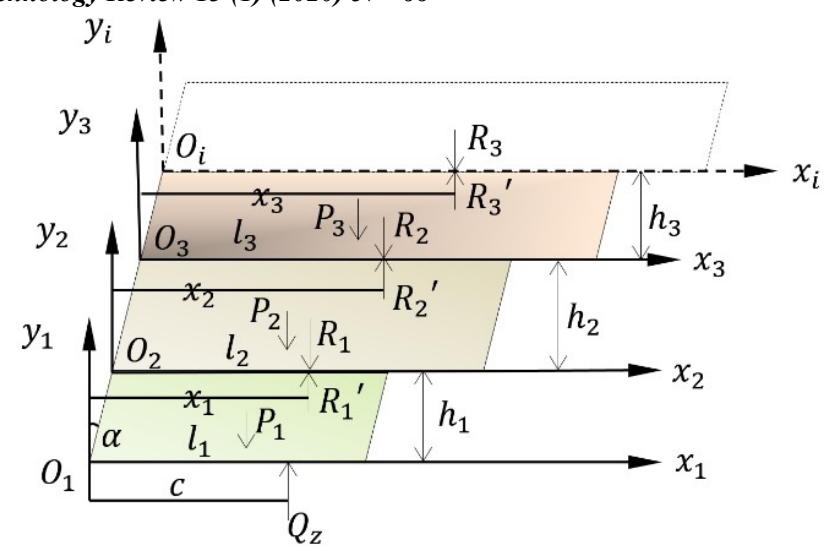

Fig. 5. Structural mechanical analysis of top coal-immediate roof

In analyzing the effect of the rock strata on the immediate roof and support resistance $Q_{z}$, Eq. (1) is expanded as a means to obtain the mechanical equilibrium equation of each rock stratum.

$\left\{\begin{array}{l}Q_{z} \cdot c-R_{1} \cdot x_{1}-P_{1}\left(\frac{l_{1}}{2}+\frac{h_{1}}{2} \tan \alpha\right)=0 \\ R_{1}^{\prime}\left(x_{1}-h_{1} \tan \alpha\right)-R_{2} \cdot x_{2}-P_{2}\left(\frac{l_{2}}{2}+\frac{h_{2}}{2} \tan \alpha\right)=0 \\ R_{2}^{\prime}\left(x_{2}-h_{2} \tan \alpha\right)-R_{3} \cdot x_{3}-P_{3}\left(\frac{l_{3}}{2}+\frac{h_{3}}{2} \tan \alpha\right)=0 \\ \vdots \\ R_{\mathrm{i}-1}^{\prime}\left(x_{\mathrm{i}-1}-h_{\mathrm{i}-1} \tan \alpha\right)-R \cdot x-P_{\mathrm{i}}\left(\frac{l_{\mathrm{i}}}{2}+\frac{h_{\mathrm{i}}}{2} \tan \alpha\right)=0\end{array}\right.$

where $x$ is the horizontal length of the rock stratum; $h_{\mathrm{j}}$ and $l_{\mathrm{j}}$ are the thickness and length of the rock mass, respectively; $\alpha$ is the rotation angle of the rock mass; $P_{\mathrm{j}}$ is the weight of the rock mass; $R_{\mathrm{j}}$ is the overlying load at the rock stratum; and $R$ is the additional load at the rock stratum on the basic roof.

$R_{\mathrm{j}}=R_{\mathrm{j}}^{\prime}(j=0,1,2, \ldots \mathrm{i})$ is set to be the internal acting force and the counterforce at the rock stratum on the immediate roof. The expression of support resistance $Q_{z}$ can be obtained as follows:

$Q_{z} \cdot c=\sum_{\mathrm{j}=1}^{\mathrm{i}} P_{\mathrm{j}}\left(\frac{l_{\mathrm{j}}}{2}+\frac{h_{\mathrm{j}}}{2} \tan \alpha\right)+\sum_{\mathrm{j}=1}^{\mathrm{i}-1} R_{\mathrm{j}} h_{\mathrm{j}} \tan \alpha+R x$

where $c$ is the distance from the resultant action point of the hydraulic supports to the coal wall.

In the analysis of the surrounding rock structure on the roof, we regard the immediate roof as a whole but neglect the internal interactive force at the rock stratum. Then, Eq. (3) can be simplified as follows:

$Q_{z} \cdot c=\sum_{\mathrm{j}=1}^{\mathrm{i}} P_{\mathrm{j}}\left(\frac{l_{\mathrm{j}}}{2}+\frac{h_{\mathrm{j}}}{2} \tan \alpha\right)+R x$

The mechanical analysis model of the hinged rock beam on the immediate roof, which is constructed according 

in Fig. 6.

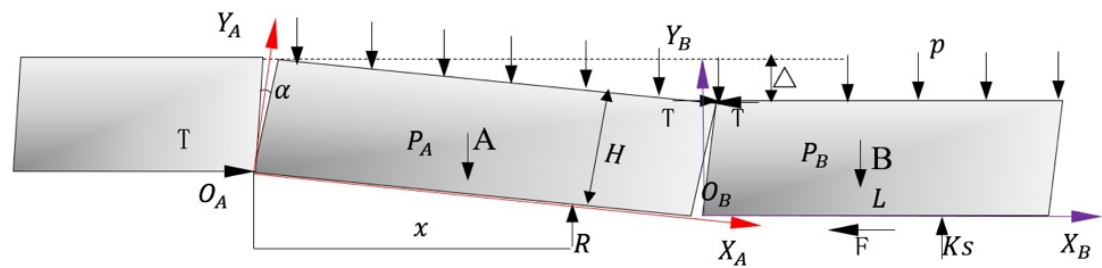

Fig. 6. Mechanical analysis of the basic roof structure

For key rock masses $\mathrm{A}$ and $\mathrm{B}$ on the basic roof, the following relation exists:

$$
\left\{\begin{array}{l}
\sum M_{\mathrm{O}_{\mathrm{A}}}=0 \\
\sum F_{\mathrm{Y}_{\mathrm{B}}}=0
\end{array}\right.
$$

where $M_{\mathrm{O}_{\mathrm{A}}}$ is the torque of key rock mass $\mathrm{A}$, and $F_{\mathrm{Y}_{\mathrm{B}}}$ is the force borne by key rock mass $B$ in the vertical direction.

The length of the rock mass is decided by its stress condition, while the periodic fracture conditions at the same rock stratum are identical. Thus, we assume that the lengths of rock masses A and B satisfy $L_{\mathrm{A}}=L_{\mathrm{B}}=L$, where $L$ is the fracturing length of the hard rock mass, which is equivalent to the cyclic weighting step. The gangues experiencing cracks and expansion will bear partial rock mass B and the weight of the rock strata and subsequently form a supporting effect on rock mass B. Moreover, this occurrence will generate a certain amount of compression s, which is mainly influenced by compaction factor $k_{1}$ and crack-expansion coefficient $k_{2}$ of the gangues and mining height. On the basis of Eq. (6), the deflection $\Delta$ of rock mass B is computed with Eq. (7).

$$
\begin{aligned}
& s=\left(k_{2}-k_{1}\right) \sum_{\mathrm{j}=1}^{\mathrm{i}} h_{\mathrm{j}} \\
& \Delta=h_{\mathrm{c}}+\left(1-k_{1}\right) \sum_{\mathrm{j}=1}^{\mathrm{i}} h_{\mathrm{j}}
\end{aligned}
$$

where $h_{\mathrm{c}}$ is the mining height of the coal seam, while $k_{1}$ can be approximated as 0.95 and $k_{2}$ as 1.3 to simplify the calculation.

According to the structural static mechanical equilibrium conditions, Eq. (5) can be expanded to obtain:

$$
\left\{\begin{array}{c}
R x-\left(P_{\mathrm{A}}+p L\right)\left(\frac{L}{2}+\frac{H}{2} \tan \alpha\right)+T(H-\Delta)=0 \\
K s L-\left(P_{\mathrm{B}}+p L\right)+T f=0
\end{array}\right.
$$

where $H$ is the thickness of the key rock mass on the basic roof, i.e., the rock stratum thickness on basic roof; $P$ is the self-weight of the key rock mass on the basic roof; $p$ is the uniformly distributed load acted by the self-weight of dynamic stratum on the basic roof; and $f$ is the friction coefficient between two rock masses.

When rock masses $\mathrm{A}$ and $\mathrm{B}$ have equal thickness, $P=p_{i+1}, L=l_{i+1}$, and $H=h_{i+1}$ can be set, and Eq. (8) is substituted by Eq. (4) to obtain the expression of the effect of the low-level hard rock stratum on support resistance $Q_{z}$ in the fully mechanized top coal mining, i.e.,

$$
Q_{z}=\frac{f \sum_{\mathrm{j}=1}^{\mathrm{i}+1} P_{\mathrm{j}}\left(l_{\mathrm{j}}+h_{\mathrm{j}} \tan \alpha\right)+f p L(L+H \tan \alpha)}{2 c f}-
$$

3.2.2 Support-surrounding rock relation under movement instability of high-level hard rock stratum With the normal mining of the 1307 fully mechanized caving face, the low-level rock stratum of the immediate roof will undergo a periodic collapse and fill the goaf. When the critical goaf filling state is reached, it will support the overlying hard rock stratum and exert a cushioning effect. Moreover, as the mining step increases and the high-level hard rock stratum reaches a certain span and deflection, fracture characteristics similar to those of the low-level rock stratum will take place. The front and rear parts of the highlevel hard rock stratum will both interact with the caving gangues (a scenario equivalent to the elastic support at the bottom), conforming with the characteristics of beams on elastic foundations [30]. Therefore, a structural model of the high-level hard rock stratum is constructed according to the theory of "elastic long beam," as shown in Fig. 7.

Fig. 8(a) presents the mechanical analysis model of the high-level hard rock stratum. As the primary rock stratum itself can form a self-supporting structure, its weight is not totally applied to the lower rock stratum. In essence, this structure mainly transfers deformational load to the lower rock stratum through the elastic foundation, influencing the stress borne by the supports on the working face. For the convenience of calculation, we assume that the amount of compression of caving rock mass D approximates that of the caving space in the rear goaf, the amount of compression of key rock mass $\mathrm{C}$ can be simplified into a linear change relation, and the amount of compression at the hinge point is zero, as shown in Fig. 8(b).

According to the theory of elastic long beam, the amount of compression $S$ of the lower caving rock strata should satisfy the following piecewise function:

$\mathrm{y}_{(x)}=\left\{\begin{array}{cc}\frac{S}{L^{\prime}} x & ; 0 \leq x \leq L^{\prime} \\ S & ; x>L^{\prime}\end{array}\right.$

where $L^{\prime}$ is fracturing step of the high-level hard rock stratum, while $x$ is the distance from the contact point between the rock mass and caving gangue to the single hinge point $\mathrm{O}$. 
The compressive stiffness of upper and lower rock strata combination (including floor, support, top coal, immediate roof, basic roof, and weak rock strata) of rock mass $\mathrm{C}$ is set to $K_{\mathrm{j}}$. The acting force $P_{(x)}$ of the rock mass on the lower elastic foundation should satisfy the following relation:

$P_{(x)}=K_{(x)} y_{(x)}=\left\{\begin{array}{c}\frac{K_{\mathrm{j}} S x}{L^{\prime}} ; 0 \leq x \leq L^{\prime} \\ K S ; x>L^{\prime}\end{array}\right.$

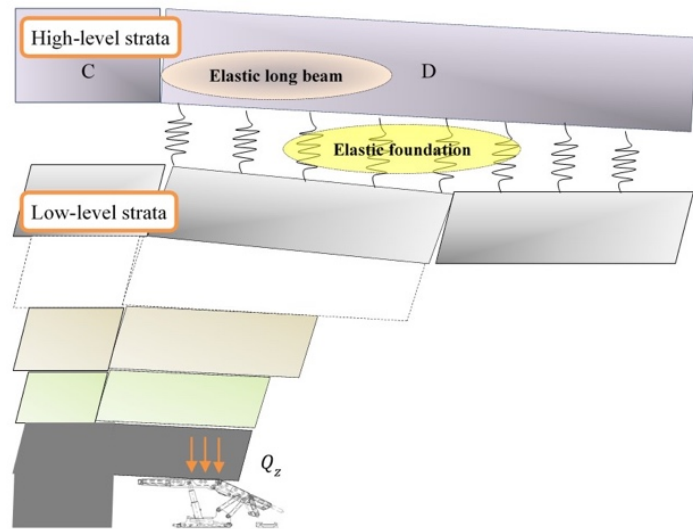

Fig. 7. Structural model of the high-level hard rock stratum

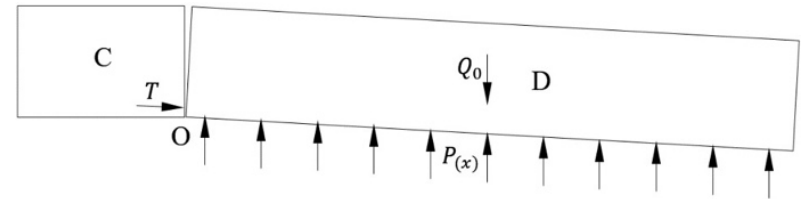

(a)

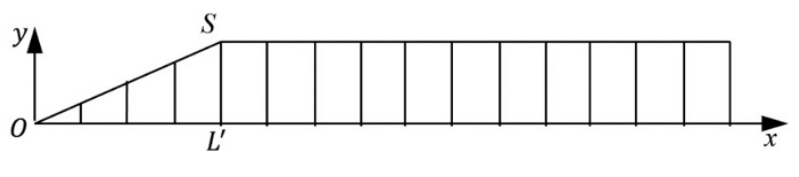

(b)

Fig. 8. Mechanical structure and deformation analysis of the high-level hard rock strata. (a) Mechanical model of key rock masses "C" and "D". (b) Amount of compression of the bottom rock strata (gangues) by the high-level hard rock stratum.

Influenced by mining, the high-level hard rock stratum will experience fracturing and instability and subsequently force the lower rock strata to undergo synchronous fracturing instability with the force transfer of the elastic foundation. Thus, we regard the lower rock strata as a combinational cantilever beam structure and the hard rock strata as a single-hinged rock beam structure, and we also regard the whole structure as one that satisfies the structural form of "combinational cantilever beam-hinged rock beam." The equation of support pressure $Q_{z}$ can be obtained according to Eq. (4) as follows:

$Q_{z} \cdot c=\sum_{\mathrm{j}=1}^{n} P_{\mathrm{j}}\left(\frac{l_{\mathrm{j}}}{2}+\frac{h_{\mathrm{j}}}{2} \tan \alpha\right)+R^{\prime} x$

where $R^{\prime}$ is the acting force of the hard roof strata structure on the lower rock strata within the scope of the roof control zone, while $n$ is the number of rock strata from the top coal to the high-level hard roof.

The rock strata below the hard roof within the scope of the roof control zone are under an acting force, which corresponds to a linear change and a triangular distribution. According to the theory of mechanics of materials, the moment acted by the hard rock strata on the lower rock strata within the scope of the roof control zone in Eq. (12) can be expressed as

$$
R^{\prime} x=\left(\frac{2}{3} K_{\mathrm{j}} S\right) \cdot\left(\frac{2}{3} L^{\prime}\right)=\frac{4}{9} K_{\mathrm{j}} S L^{\prime}
$$

Eq. (13) is then substituted with Eq. (12) to obtain the calculation equation of the effect of the high-level hard rock strata on rock resistance $Q_{z}$ in the fully mechanized top coal caving, i.e.,

$$
Q_{z}=\frac{\sum_{\mathrm{j}=1}^{n} P_{\mathrm{j}}\left(l_{\mathrm{j}}+h_{\mathrm{j}} \tan \alpha\right)}{2 c}+\frac{4 K_{\mathrm{j}} S L^{\prime}}{9 c}
$$

As for the periodic instability step of the hinged rock beam, Qian [11] emphasized that a change in rotation angle of a key rock mass will directly affect its rotational deformation instability step. The calculation equation of rotation angle $\alpha$ is shown in Eq. (15), which can be obtained when the hinged rock beam structure satisfies Eq. (16). A steady state exists, and the gradual increase in rotation angle $\alpha$ will eventually lead to the rotational deformation instability of the rock mass. The maximum value of length $l$ of rock mass corresponds to the rotational deformation instability step.

$$
\sin \alpha=\frac{1}{l}\left[h_{\mathrm{c}}-h\left(k_{1}-1\right)\right]
$$

where $h$ is the thickness of the hard rock strata.

$$
h+h_{1} \leq \frac{0.15 \sigma_{c}}{\rho g}\left[\left(\frac{h}{l}\right)^{2}-\frac{3}{2}\left(\frac{h}{l}\right) \sin \alpha+\frac{1}{2} \sin ^{2} \alpha\right]
$$

where $h_{1}$ is the thickness of the supported rock stratum in the hard rock strata; $\rho$ is the apparent density of the hard rock strata; and $\sigma_{c}$ is the compressive strength of the hard rock strata.

Eq. (15) is substituted with Eq. (16) to obtain periodic rotational deformation instability step of the hard rock strata, i.e.,

$l \leq \sqrt{\frac{0.15 \sigma_{c} \cdot\left[2 h^{2}-3 h\left(h_{c}-h\left(k_{1}-1\right)\right)+\left(h_{c}-h\left(k_{1}-1\right)\right)^{2}\right]}{2 \rho g\left(h+h_{1}\right)}}$

\section{Result analysis and discussion}

\subsection{Influence laws of overlying strata movement on support resistance}

The effects of changes in thickness $h$ and length $l$ of the rock mass on rotation angle, instability step, and support 
Wenbao Shi, Zhiqiang Yin, Yan Li, Jucai Chang and Xianhua Miao/

Journal of Engineering Science and Technology Review 13 (1) (2020) 57 - 66

resistance are analyzed by combining Eqs. (9), (4), (15) and (17), as shown in Figs. 9 and 10, respectively.

As shown in Figs. 9(a) and (b), when the thickness of the low-level hard rock strata increases from 5 to $25 \mathrm{~m}$, the length of the rock mass under rotational deformation instability will increase from 17 to $38 \mathrm{~m}$, and the rotation angle will decline from $11.8^{\circ}$ to $10.6^{\circ}$. Moreover, when the thickness of the high-level hard rock strata increases from 5 to $25 \mathrm{~m}$, the rotational deformation instability length of the rock mass will increase from 60 to $140 \mathrm{~m}$, and the rotation angle will decline from $13.6^{\circ}$ to $11.7^{\circ}$. These findings on the thickness change in the rock strata indicate that the instability step and the rotation angle of the high-level hard rock strata are essentially similar to those of the low-level hard rock strata, but the effect of rock strata thickness on the step and rotation angle under rotational instability of the high-level hard rock strata is more significant. By taking the 1307 working face in Zhaoxian Coal Mine as the example, we find that the thickness of the low-level hard rock strata in this mine is $7.8 \mathrm{~m}$, whereas that of the high-level rock strata is $24.37 \mathrm{~m}$, and their rotational deformation instability steps are 18 and $106 \mathrm{~m}$, respectively. Therefore, the high- and low-level hard rock strata on the 1307 fully mechanized caving face in Zhaoxian Coal Mine present different periodic instability steps.

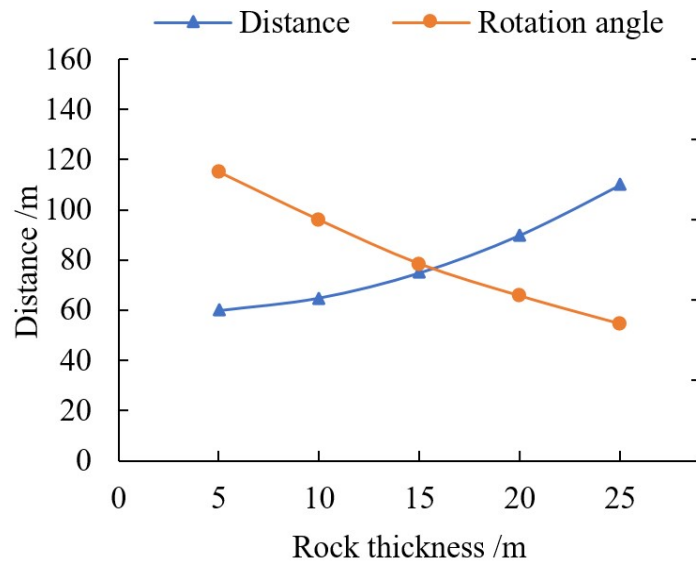

(a)

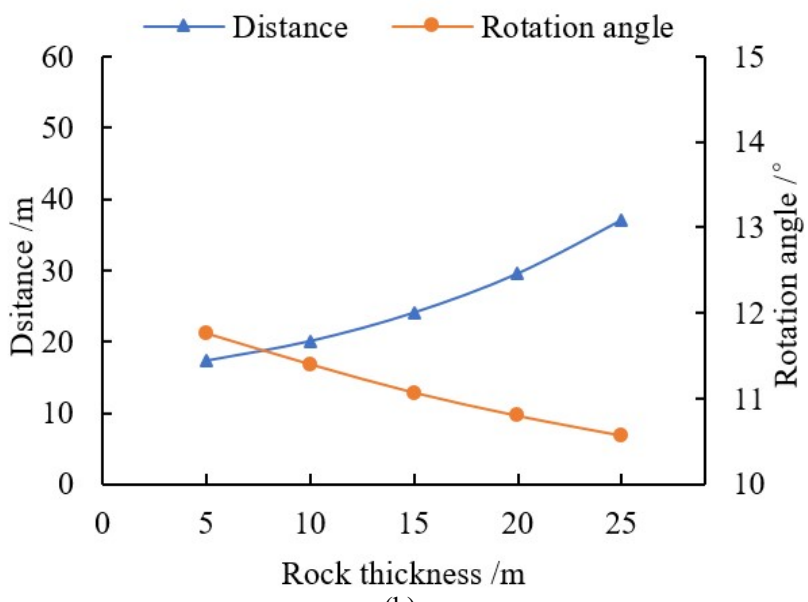

(b)

Fig. 9. Change curves of periodic instability steps of the high- and lowlevel hard rock strata. (a) Effect of thickness of the low-level hard rock strata on instability step. (b) Effect of thickness of the high-level hard rock strata on instability step.

A comparison of Figs. 10(a) and (b) shows that support resistance linearly changes with the increase in mining step. In the high-level hard rock strata structure, the support resistance is first gentle and then changes suddenly with the increase in mining step. When the thickness of the low-level hard rock strata increases from 5 to $25 \mathrm{~m}$, the instability step will increase from 17 to $38 \mathrm{~m}$, and the support resistance under instability will increase from 36 to $48 \mathrm{MPa}$ (a onethird increase). When the instability step of the high-level hard rock strata increases from 60 to $110 \mathrm{~m}$, the support resistance under instability will increase from 33 to 64.5 $\mathrm{MPa}$ (nearly a doubled increase). The above difference indicates that the thickness of the rock mass evidently influences support resistance, and the effect on the mechanical model of the high-level hard rock strata is much more remarkable. Then, we take again the 1307 working face of Zhaoxian Coal Mine as the example. As shown in Fig. 10, the working resistances of the hydraulic support under the periodic instability of the high- and low-level hard rock strata are approximately 63 and $37 \mathrm{MPa}$, respectively.

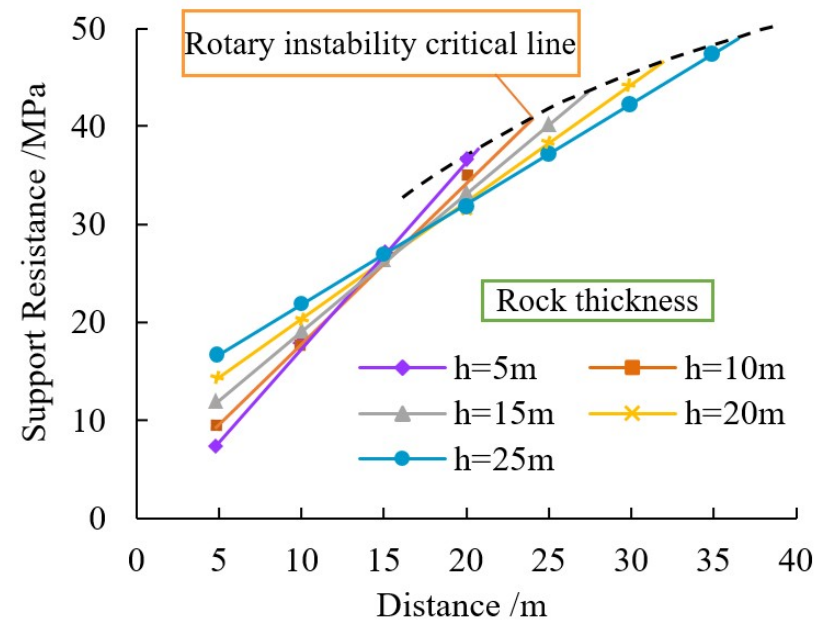

(a)

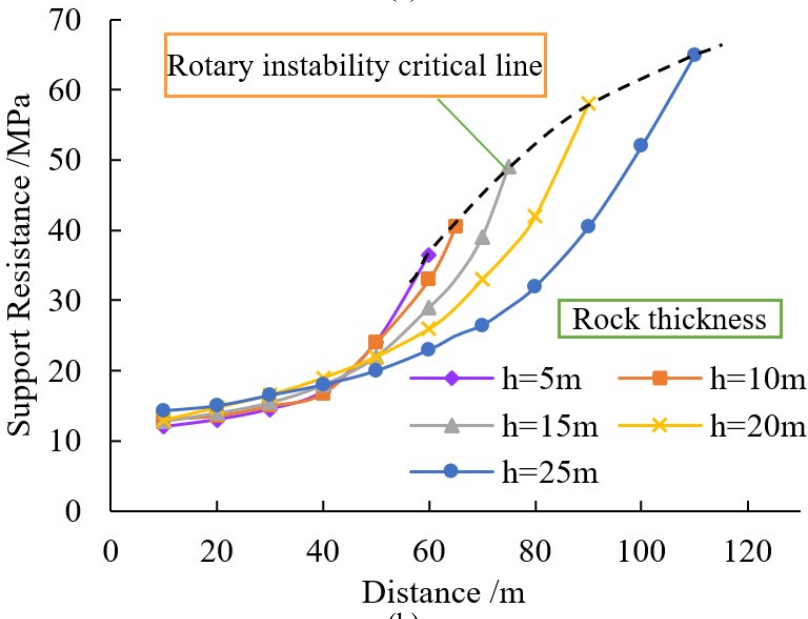

(b)

Fig. 10. Change curves of working resistance of the hydraulic support. (a) Effect of low-level hard rock strata on support resistance. (b) Effect of high-level hard rock strata on support resistance.

In summary, when the mining step is small, the instability of the low-level hard rock strata becomes the primary cause of the increase in support resistance, and periodic rotational deformation instability occurs with the mining of the working face. When the mining step of this working face exceeds $106 \mathrm{~m}$, the high-level hard roof will experience instability and further influence the low-level rock strata, and the support resistance on the working face will abruptly increase by approximately $26 \mathrm{MPa}$. In the fully mechanized top coal mining process of the hard roof, its mine pressure behaviors will feature "major- and minorcycle weighting." 
4.2 Field monitoring of mine pressure behaviors under the movement instability of the overlying strata

After the monitoring results of the hydraulic supports on the working face from December 11, 2017 to February 11, 2018 (two months) were calculated and organized, the change in support resistance was obtained (Fig.11). The support resistance started to rise from December 24, 2017, and the initial weighting intensity on the working face was $38.4 \mathrm{MPa}$ within a short duration (15h). With the two cyclic weightings on December 28 and January 2, the working face experienced strong mine pressure since January 10, 2018, the support resistance reached $41.7 \mathrm{MPa}$, and the weighting step was $108.7 \mathrm{~m}$ with a duration of $73 \mathrm{~h}$. The safety valve started a pressure relief within a large area that lasted a long time.
The statistical results of the weighting step and the intensity on the working face are shown in Table 1 . The minor-cycle weighting step was in the range of 15-25 m with an average continuous weighting step of approximately $2 \mathrm{~m}$, and the average major-cycle weighting step was $101 \mathrm{~m}$ with a continuous step of approximately $12 \mathrm{~m}$. The corresponding average peak support resistances were 36.8 and $42.3 \mathrm{MPa}$. The weighting step and weighting intensity distribution laws of working face accord with the previous analysis on the influence laws on the movement of high- and low-level hard rock strata on support resistance. Thus, compared with the "minor-cycle" phenomenon, the majorcycle weighting manifested greater weighting step, stronger weighting behavior, and longer duration.

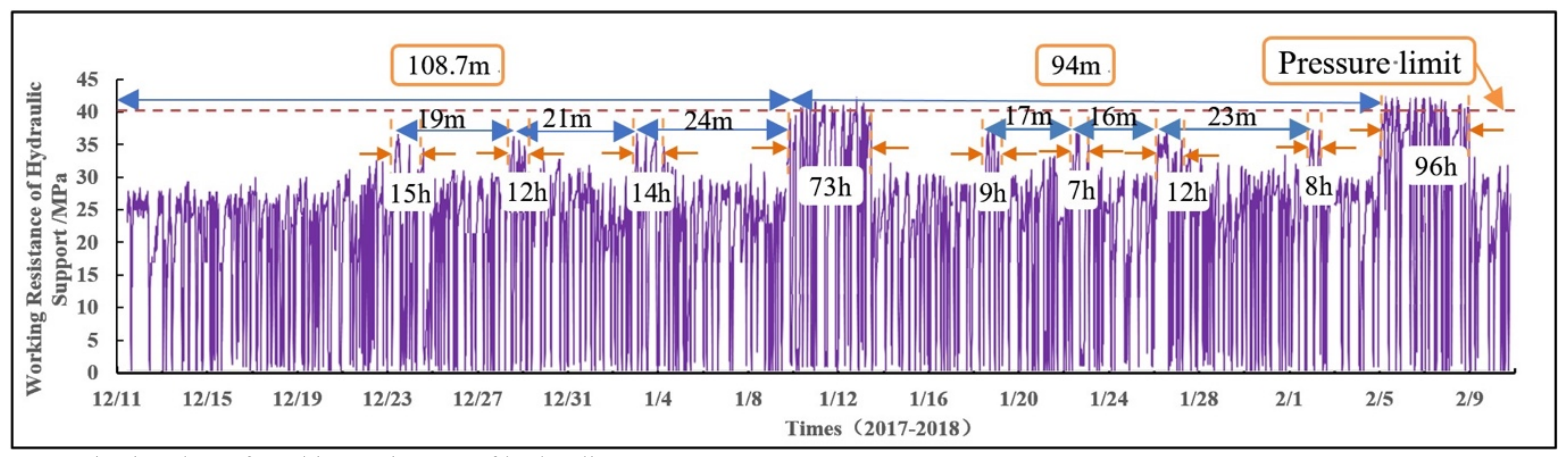

Fig. 11. Monitoring data of working resistance of hydraulic supports

Table. 1. Statistical results of cyclic weighting of the working face

\begin{tabular}{c|c|c|c|c}
\hline Cyclic weighting date (2017-2018) & Weighting step(m) & Duration(h) & Continuous step(m) & Peak pressure(MPa) \\
\hline 12.28 & 19 & 15 & 2.1 & 36.1 \\
1.2 & 21 & 14 & 2.0 & 36.7 \\
1.10 & 24 & 73 & 10.6 & 41.7 \\
1.18 & 25 & 7.2 & 37.3 \\
1.23 & 17 & 12 & 1.0 & 37.8 \\
1.26 & 16 & 8 & 1.8 & 36.4 \\
2.2 & 24 & 96 & 1.2 & 36.8 \\
2.5 & 13 & 27.1 & 4.0 & 42.8 \\
\hline Average & 22.6 & & & 39.7 \\
\hline
\end{tabular}

4.3 Structural instability model of overlying strata in fully mechanized top coal mining of a double-stratum hard roof

The field monitoring data on support resistance verified the different movement instability characteristics of the highand low-level hard rock strata on the fully mechanized caving face, and the change laws of support resistance presented a "major- and minor-cycle" phenomenon. Then, the geological conditions and the compound key strata structures of the high- and low-level hard rock strata were considered. The structural instability evolution characteristics of the overlying strata on the fully mechanized top coal caving of the multi-stratum hard roof are shown in Fig. 12. This study assumes that the overlying strata structure in the fully mechanized top coal mining of this multi-stratum hard roof experienced instability for the following reasons:

\section{(1) Effect of low-level hard rock strata on high-level hard} rock strata

With the advancement of the working face, the low-level rock strata experienced periodic fracturing instability and caving under the action of overlying load. As the fully mechanized mining height was large, the low-level caving rock masses failed to fill the goaf in a timely manner, and the caving height of the overlying strata was likely to further develop upward and subsequently influence the high-level hard rock strata. As the mining step increased, the high-level hard rock strata were supported by the elastic foundation of the lower loose rock strata. When the high-level hard rock strata experienced bending deformation and deflection, and a fracture surface was generated, the formed fracturing rock masses were likely to rotate under gravity force. Meanwhile, an "elastic long beam" support structure was formed due to the extrusion between the rock masses. Consequently, mining-induced cracks slowly developed upward from the low-level rock strata, finally leading to a time-lag characteristic of instability for the high- and low-level hard rock strata.

\section{(2) Rotational deformation instability of high-level hard rock strata}

After the extruding stress between the contact faces of the rock masses at the high-level hard rock strata exceeded the compressive strength of the rock masses, the high-level rock strata were likely to experience extruding failure, which could lead to rotational deformation instability. The overlying bearing weight was transferred from the elastic foundation to the low-level rock strata. Subsequently, the high-level hard rock strata caused the low-level rock strata to undergo linkage-type instability, leading to periodic strong mine pressure behaviors. 


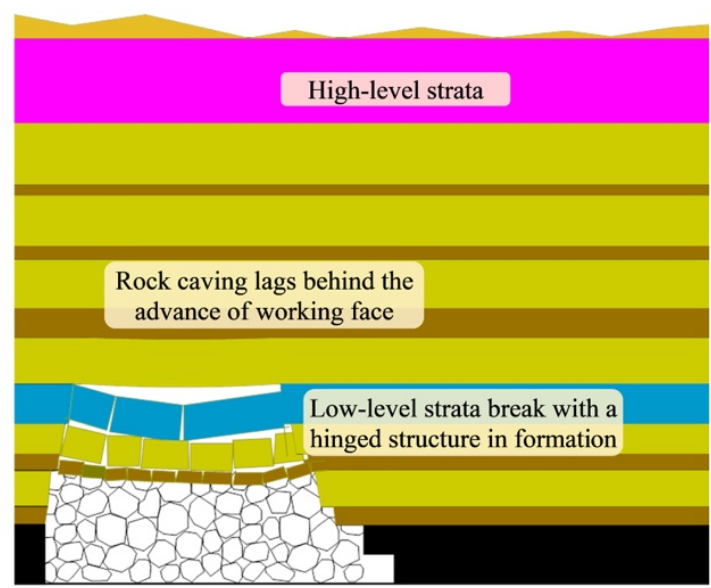

"Cantilever beam + hinged rock beam" structure formed by breaking of low-level strata

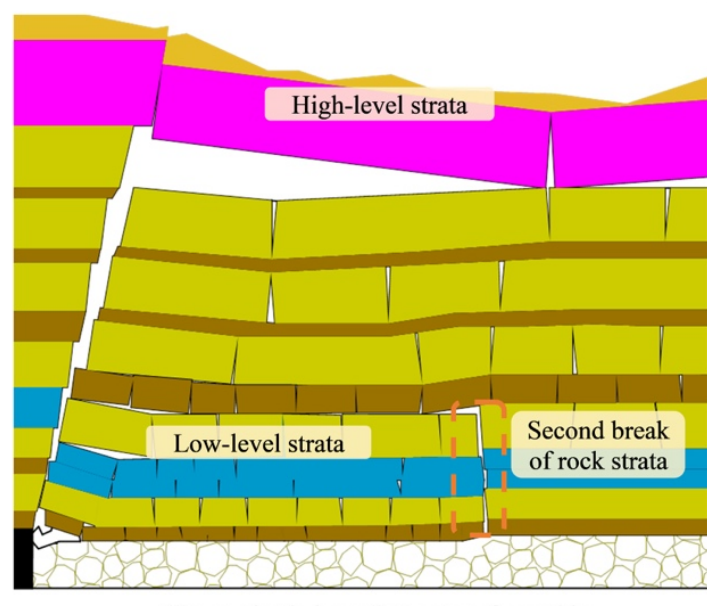

"Long elastic beam" structure formed by breaking of high-level strata

Fig. 12. Schematic diagram of instability characteristics of the overlying strata structure of the multi-stratum hard roof

\section{Conclusions}

Under the background of geological and mining conditions of the 1307fully mechanized caving face in Zhaoxian Coal Mine, the fracturing instability characteristics of high- and low-level double-stratum hard roofs were analyzed on the basis of the theoretical models of elastic mechanics and fracture mechanics. Support pressure monitoring recorders were used to realize the field-monitored working resistance of the hydraulic supports and the overlying structural instability model of the fully mechanized top coal caving of the double-stratum hard roof. The change laws of working resistance of the hydraulic supports were obtained. The concrete conclusions can be drawn as follows:

(1) The fracturing structure of the double-stratum hard roof on the fully mechanized caving face can be divided into two structural characteristics: high- and low-level hard roofs. Mechanical models for the different strata levels were constructed according to "elastic long beam" theory and "combinational cantilever beam-hinged rock beam" theory. The characteristics of the overlying strata fracturing step and the working resistance of the hydraulic supports are determined. We find that mine pressure behaviors in the fully mechanized top coal mining of the double-stratum hard roof will likely leads to "major- and minor-cycle weighting" phenomena.

(2) On the basis of the field monitoring, the changes in the working resistance of the hydraulic supports occur in major and minor cycles, verifying that the periodic instability characteristics of the double-stratum hard roof in the fully mechanized top coal caving are identical with the theoretical analytical results, further proving that a majorcycle weighting of the working face has larger weighting step, higher weighting intensity and longer duration.

(3) The structural instability of the "elastic long beam" at the high-level hard rock strata on the fully mechanized caving face always leads to a linkage-type caving of the lowlevel rock strata, further causing strong cyclic mine pressure behaviors in the fully mechanized top coal caving of the hard roof. This phenomenon is the primary reason of the upward and periodical compression of the hydraulic supports by a large margin on the working face.

The overlying strata structure with a fixed spacing of two-stratum hard roofs was investigated in this study. The influence laws of spacing of different multi-stratum hard roofs on support resistance may be further examined via a follow-up research. Future findings may contribute to the deep understanding of structural evolution laws of multistratum hard roofs in the mining process and provide a basis for safe and high-efficiency mining of the working face.

\section{Acknowledgements}

The authors are grateful for the support provided by the National Natural Science Foundation of China (51874006 and 51774009) and Anhui Provincial Natural Science Foundation (1808085ME134).

This is an Open Access article distributed under the terms of the Creative Commons Attribution License

\section{References}

1. Huang, J., Tian, C., Xing, L., "Green and Sustainable Mining: Underground Coal Mine Fully Mechanized Solid Dense StowingMining Method". Sustainability, 2017, 9(8), pp. 1-11.

2. Rakesh, K., Kumar, S. A., Kumar, M. A., "Underground Mining of Thick Coal Seams". International Journal of Mining Science and Technology, 2015, 25(6), pp. 885-896.

3. Yu, L., "Study On Abutment Pressure Distribution Law of FullyMechanized Sublevel Caving Face in Extra-Thickness". Advanced Materials Research, 2015, 1094(1), pp. 405-409.

4. Vakili, A., Hebblewhite, B. K., "A New Cavability Assessment Criterion for Longwall Top Coal Caving". International Journal of Rock Mechanics and Mining Sciences, 2010, 47(8), pp. 1317-1329.
5. Da Veiga, L., David Mora, and Gonzalo Rivera.. "Virtual Elements for a Shear-Deflection Formulation of Reissner-Mindlin Plates". Mathematics of Computation, 2019, 88(315), pp. 149-178.

6. Konda, D. H., Santiago, J. A. F., Telles, J. C. F., "A Meshless Reissner Plate Bending Procedure Using Local Radial Point Interpolation with an Efficient Integration Scheme". Engineering Analysis with Boundary Elements, 2019, 99, pp. 46-59.

7. Höller, R., Aminbaghai, M., Eberhardsteiner, L., "Rigorous Amendment of Vlasov's Theory for Thin Elastic Plates On Elastic Winkler Foundations, Based On the Principle of Virtual Power". European Journal of Mechanics a: Solids, 2019, 73, pp. 449-482. 
Wenbao Shi, Zhiqiang Yin, Yan Li, Jucai Chang and Xianhua Miao/

\section{Journal of Engineering Science and Technology Review 13 (1) (2020) 57 - 66}

8. Vlasov, V. S., Kirushev, M. S., Shavrov, V. G., "Forced Nonlinear Precession of the Second-Order Magnetization in a Magnetoelastic Material". Journal of Communications Technology and Electronics, 2019, 64(1), pp. 41-51.

9. Zhao T, Liu C, Yetilmezsoy K, "Fractural Structure of Thick Hard Roof Stratum Using Long Beam Theory and Numerical Modeling". Environmental Earth Sciences, 2017, 76(21), pp. 751.

10. Sulem, J. S. C. E., Ouffroukh, H., "Shear Banding in Drained and Undrained Triaxial Tests On a Saturated Sandstone: Porosity and Permeability Evolution". International Journal of Rock Mechanics and Mining Sciences, 2006, 43(2), pp. 292-310.

11. Minggao, Q., Xu, J., "Behaviors of Strata Movement in Coal Mining”. Journal of the China Coal Society, 2019, 44(4), pp. $973-$ 984.

12. Li, B., Liang, Y., Zou, Q., "Determination of Working Resistance Based On Movement Type of the First Subordinate Key Stratum in a Fully Mechanized Face with Large Mining Height". Energy Science and Engineering, 2019, 7(3), pp. 777-798.

13. Verma, A. K., Deb, D., "Longwall Face Stability Index for Estimation of Chock-Shield Pressure and Face Convergence". Geotechnical and Geological Engineering, 2010, 28(4), pp. 431445.

14. Verma, A. K., Deb, D., "Effect of Lithological Variations of Mine Roof On Chock Shield Support Using Numerical Modeling Technique". Journal of Scientific and Industrial Research, 2006, 65, pp. 702-712.

15. Golab, A. N., Hutton, A. C., French, D., "Study of Roof Stability of the End of Working Face in Upward Longwall Top Coal". Arabian Journal of Geosciences, 2017, 10(8), pp. 185

16. Chen, B., Liu, C., Yang, J., "Design and Application of Blasting Parameters for Presplitting Hard Roof with the Aid of Empty-Hole Effect". Shock and Vibration, 2018, 2018, pp. 1-13.

17. Sainsbury, B.L., "A Sub-Level Caving Algorithm for Large-Scale, Small-Strain, Numerical Simulations". Rock Mechanics and Rock Engineering, 2019, 52(1), pp. 289-295.

18. Wang, X., Qin, Q., Fan, C., "Failure Characteristic and Fracture Evolution Law of Overburden of Thick Coal in Fully Mechanized Sub-Level Caving Mining”. Sains Malaysiana, 2017, 46(11), pp. 2041-2048.

19. Zhou, D., Wu, K., Bai, Z., "Formation and Development Mechanism of Ground Crack Caused by Coal Mining: Effects of Overlying Key Strata”. Bulletin of Engineering Geology and the Environment, 2019, 78(2), pp. 1025-1044.
20. Li, J., Huang, Y., Zhang, J., "The Influences of Key Strata Compound Breakage On the Overlying Strata Movement and Strata Pressure Behavior in Fully Mechanized Caving Mining of Shallow and Extremely Thick Seams: A Case Study". Advances in Civil Engineering, 2019, 2019, pp. 1-9.

21. Zhang, Z., Bai, J., Chen, Y., "Shallow-Hole Blasting Mechanism and its Application for Gob-Side Entry Retaining with Thick and Hard Roof'. Chinese Journal of Rock Mechanics and Engineering, 2016, 2016(S1), pp. 3008-3017.

22. Guo, W., Wang, H., Dong, G., "A Case Study of Effective Support Working Resistance and Roof Support Technology in Thick Seam Fully-Mechanized Face Mining with Hard Roof Conditions". Sustainability, 2017, 9(6), pp. 1-12.

23. Mangal, A., Paul, P. S., "Rock Mechanical Investigation of Strata Loading Characteristics to Assess Caving and Requirement of Support Resistance in a Mechanized Powered Support Longwall Face". International Journal of Mining Science and Technology, 2016, 26(6), pp. 1081-1087.

24. Liang, S., Elsworth, D., Li, X., "Key strata characteristics controlling the integrity of deep wells in longwall mining areas". International Journal of Coal Geology, 2017, 172, pp. 31-42.

25. Kornowski, J., Kurzeja, J., "Prediction of Rockburst Probability Given Seismic Energy and Factors Defined by the Expert Method of Hazard Evaluation (Mrg)". Acta Geophysica, 2012, 60(2), pp. 472-486.

26. Xu, Y. C., Li, J. C., Liu, S. Q., "Calculation Formula of "TwoZone" Height of Overlying Strata and its Adaptability Analysis". Coal Mining Technology, 2011, 16(2), pp. 4-7.

27. Li, M., Zhang, J., Huang, Y., "Measurement and Numerical Analysis of Influence of Key Stratum Breakage On Mine Pressure in Top-Coal Caving Face with Super Great Mining Height". Journal of Central South University, 2017, 24(8), pp. 1881-1888.

28. Wang, X., Wang, Y., Zhang, D., "Characteristics of Strata Behavior During Thick Seam Mining by Fully-Mechanized Top Coal Caving in a Loess-Covered Gullied Region”. Minerals, 2017, 7(4), pp. 1-8.

29. Liyan, H., Siyuan, C., Yugang, L., "Structural Mechanics". Harbin: Heilongjiang University Press, China, 2010.

30. Tong, X., Peng, C., Zhang, J., "Study on the Enhancement Coefficient of the Local Compressive Strength Improvement of Masonry Under a Cantilever Beam". Case Studies in Construction Materials, 2019, 11, pp. 1-8. 